\title{
Sustainable low-carbon binders and concretes
}

\author{
Myroslav Sanytsky ${ }^{1, *}$, Tetiana Kropyvnytska ${ }^{1}$, Stanislav Fic $^{2}$, and Hanna Ivashchyshyn ${ }^{1}$ \\ ${ }^{1}$ Lviv Polytechnic National University, Department of Building production, 12 Bandera Str., 79013, Ukraine \\ ${ }^{2}$ Lublin University of Technology, Department of Building Structures, 40 Nadbystrzycka Str., 20-618, Poland
}

\begin{abstract}
Sustainable development depends on a consistency of interests, social, ecological and economic, and that the interests are evaluated in a balanced manner. In order to reduce $\mathrm{CO}_{2}$ emissions, the conception of decreasing clinker factor and increasing the role of supplementary cementitious materials (SCMs) in the cementitious materials has high economical and environmental efficiency. The performance of clinkerefficient blended cements with supplementary cementitious materials were examined. The influence of superfine zeolite with increased surface energy on the physical and chemical properties of low-carbon blended cements is shown. Increasing the dispersion of cementitious materials contributes to the growth of their strength activity index due to compaction of cement matrix and pozzolanic reactions in unclincker part. In consequence of the early structure formation and the directed formation of the microstructure of the cement matrix is solving the problem of obtaining clinker-efficient concretes. Shown that low-carbon blended cements with high volume of SCMs are suitable, in principle, for producing structural concretes.
\end{abstract}

\section{Introduction}

The development of civilization, such as urban expansion or infrastructure development, has a significant environmental impact. Excessive consumption of energy leads to a significant increase in the amount of carbon dioxide in the atmosphere, which causes climate change and threatens the future of humanity. At the same time there are problems of waste disposal and reduction of consumption of natural raw materials. Therefore, the crucial topic of the functioning of civilization in the XXI century is the concept of sustainable development $[1,2]$. The priorities identified at the World Summit on Sustainable Development are the integration of these three components: economic growth, social development and environmental protection. Currently, the challenge of introducing principles of sustainable development in the construction sector, especially in the industry of construction materials, is extremely urgent. This implies the creation of technical prerequisites that form the basis for the development and implementation of effective measures to improve the energy efficiency of construction technologies in accordance with environmental requirements, taking into account the full life cycle of products and objects. The basic principles of sustainable development strategy in the cement industry are to optimize the usage of non-renewable natural raw materials: the implementation of resource-saving technologies; utilization of industrial waste, as well as comprehensive environmental protection and reduction of $\mathrm{CO}_{2}$ emissions [3-6].

The Paris Agreement was adopted in accordance with the UN Framework Convention on Climate Change
(UNFCCC) in order to regulate carbon dioxide reduction measures from 2020 replacing the Kyoto Protocol. This climate agreement stipulates that commitments to reduce harmful greenhouse gas emissions to the atmosphere and not to exceed rising temperatures above 2 degrees Celsius shall be observed by all states, regardless of their level of economic development.

The EU's priority is to reduce greenhouse gas emissions by $80-95 \%$ by 2050 . The cement industry produces a significant amount of greenhouse gases, accounting for 2-2.5 gigatons of $\mathrm{CO}_{2}$ or $6.5 \%$ of the total anthropogenic emissions worldwide. Integrated cement industry solutions for sustainable development policies aim at reducing $\mathrm{CO}_{2}$ emissions by reducing high-energy Portland cement clinker in composition of cement by utilizing industrial waste, improving production technology and using alternative fuels. Additional emission reductions can be achieved through the use of new technologies such as carbon capture and storage (CCS) and low carbon cement replacement components [7]. With this policy and technological prerequisites, a potential reduction in $\mathrm{CO}_{2}$ emissions of up to $80 \%$ can be achieved [8]. The production of hightech products in the construction industry, taking into account the reduction of environmental pollution, is largely realized through the introduction of effective low-emission (low-carbon) cements and concretes based on them [7].

The EU Roadmap 2050 on low-carbon economy with regards to cement and concrete industry envisages five parallel directions, each contributing to the reduction of $\mathrm{CO}_{2}$ emissions. According to the roadmap, the first direction involves reduction of the usage of natural resources, increasing the share of alternative fuels,

* Corresponding author: msanytsky@ukr.net 
replacing clinker with mineral components and introducing new types of cement, which will allow to replace a significant proportion (up to $80 \mathrm{wt} . \%$ ) of highenergy Portland cement clinker in cement-containing materials. including production wastes. The use of SCMs in cement production has a positive impact on the economic aspect of production and, crucially, is a significant factor in improving the environment. On the other hand, the use of industrial waste can reduce the consumption of natural raw materials, reduce $\mathrm{CO}_{2}$ emissions and free up useful soils, which will reduce the risk of man-made disasters and contribute to the energy independence of the national economy [8].

The family of common cements according to EN 197-1 are divided into five types: CEM I - Portland cement; CEM II - Portland cement with additives; CEM III - slag Portland cement; CEM IV - pozzolanic cement; CEM V - composite cement. Portland cement CEM I can contain up to 5 wt.\% of mineral additives. The content of mineral additives in cement from CEM II to CEM V can vary over a wide range - from 6 to 80 wt.\%. In the European standard EN 197-1 are selected as a separate type of composite cements, which according to the requirements must contain at least two types of mineral constituents of different nature of activity (hydraulic and pozzolanic action).

The solution to the problem of energy saving and reduction of $\mathrm{CO}_{2}$ emissions in the cement industry is largely determined by the search for structural, logical and environmental ways of replacing part of the Portland cement clinker with secondary components with optimization of particle size and material composition of cement. The result of such efforts is a plan of amendments to the standard for general purpose cements EN 197-1 regarding the introduction of new types of composite cements of types CEM II/C and CEM VI [9].

Due to the environmental impact of the cement industry in the direction of sustainable development, by selecting appropriate combinations of non-clinker components in low-carbon cements will be an alternative to traditional cements [10-13]. At the same time, more and more attention are paid to the production of lowcarbon concretes. The evaluation of the environmental impact indicator for binary and ternary cements has made it possible to determine their suitability for the production of low-carbon concrete.

The concept of creating modified concretes and mortars involves the use of multicomponent cements with a high content of SCMs and optimization of their component composition and particle size distribution due to the combination of mineral components of natural and man-made origin, nanoadditives and alkaline activation [14-17]. This will facilitate the acceleration of hydraulic and pozzolanic reactions in the SCMs system; improving the transition zone between the cement matrix and the aggregate. Increasing the content of finely dispersed energy-active fractions in the SCMs will increase the surface area of the active phases, which increases the rheological effect of the polycarboxylate modifier on the mixture. The effectiveness of this idea is to maximize the disclosure of the synergistic role of ultrafine mineral components in low-emission multicomponent cements, which will have a direct impact on the processes of regulating the properties of clinker-efficient concretes.

According to data from K. L. Scrivener et al. [5], binder intensity for concretes with a strength of $60 \mathrm{MPa}$ should be within the range of $2-5 \mathrm{~kg}$ per $1 \mathrm{MPa}$ of concrete strength (Fig. 1). Binder intensities around 4-5 $\mathrm{kg} / \mathrm{m}^{3} \cdot \mathrm{MPa}$ can be achieved for $50 \mathrm{MPa}$ concretes and more with by optimizing the component composition of concrete and using new generation water-reducing admixture. Similar way can be deployed for mortars, concrete blocks and other cement-based products.

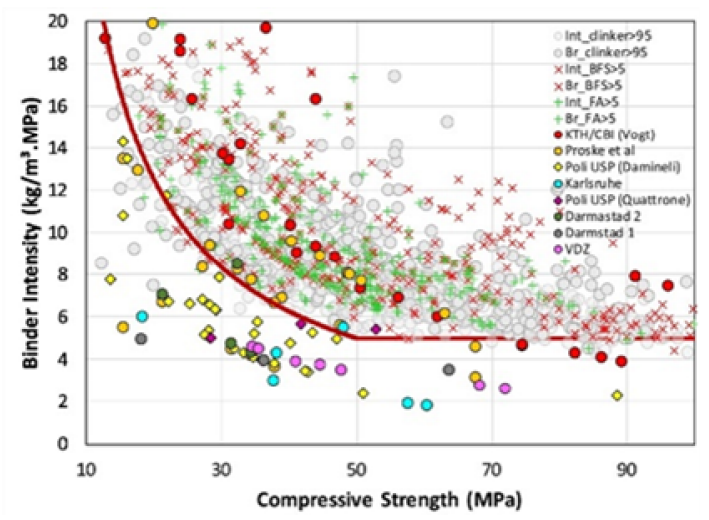

Fig. 1. Potential $\mathrm{CO}_{2}$ mitigation by optimizing binder use with current and high-filler, low-water technologies [7].

In advanced $\mathrm{EU}$ countries, $\mathrm{CO}_{2}$ emissions for concrete have been reduced by $19.1 \%$ and account for $83.4 \mathrm{~kg}$ of $\mathrm{CO}_{2}$ per tonne of concrete. To reduce $\mathrm{ECO}_{2}$, it is also foreseen to replace the proportion of Portland cement CEM I pure cement in concrete with multicomponent SCMs, which is an actual way to achieve a sustainable development in construction.

\section{Materials and methods of research}

\subsection{Materials}

Commercially available Ordinary Portland cement (OPC) CEM I 42.5R (Manufacturer - JSC "IvanoFrankivsk Cement", Ukraine) was used as reference cement in the investigation. The contents of the main clinker phases were as follows, mass. $\%: \mathrm{C}_{3} \mathrm{~S}-60.2$; $\mathrm{C}_{2} \mathrm{~S}-4.25 ; \mathrm{C}_{3} \mathrm{~A}-7.20 ; \mathrm{C}_{4} \mathrm{AF}-11.85$. Supplementary cementitious materials as ground granulated blast furnace slag (GGBFS, Kryvyi Rih), zeolite tuff (Z, Sokyrnytsky quarry), fly ash (FA, Burshtyn TPP), and limestone powder (LL, Dubivetske quarry) were used to obtain low emission binders. The chemical composition of SCMs is shown in Fig. 2.

Building binder G-6 brand based on calcium sulphate hemihydrate $\left(\mathrm{CaSO}_{4} \cdot 0.5 \mathrm{H}_{2} \mathrm{O}\right)$ was used for development low-carbon gypsum binder.

The high-performance Master Glenium ACE 430 (BASF) polycarboxylate ether (PCE) superplasticizer was used as a modifier for concrete and air-entraining admixture MasterAir 81 (BASF) was used to improve the quality parameters of mortars. 


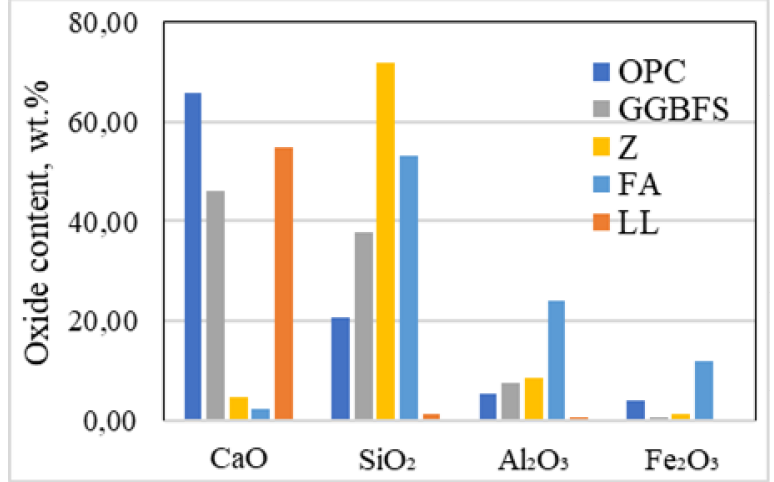

Fig. 2. Chemical composition of SCMs.

Sand of Zhovkva deposit, Ukraine, was used as fine aggregates (FA) and crushed stone of Virovske deposit, Ukraine, as coarse aggregates (CA) were used to design of mixture compositions.

Blended cements (CEM II/B-M, CEM IV/B, CEM $\mathrm{V} / \mathrm{A}, \mathrm{MC} 22.5 \mathrm{X}$ ) with the different ratio between Portland cement CEM I 42.5R and supplementary cementitious materials were used in experiments (Table 1).

Table 1. The composition of cements.

\begin{tabular}{|c|c|c|c|c|c|c|}
\hline Cement & Clinker factor & OPC & GGBFS & Z & FA & LL \\
\hline CEM I & 0,95 & 100 & - & - & - & - \\
\hline CEM II/B-M & 0,65 & 65 & 20 & 10 & - & 5 \\
\hline CEM IV/B & 0,50 & 50 & - & 27 & 23 & - \\
\hline CEM V/A & 0,50 & 50 & 25 & 20 & - & 5 \\
\hline MC 22.5X & 0,40 & 40 & - & 40 & - & 20 \\
\hline
\end{tabular}

\subsection{Methods}

Investigation of the chemical composition of OPC and SCMs was carried out using an X-ray diffractometry ARL (OPTIM'X) 9800XP. Blended cements were obtained by mixing OPC and SCMs in a laboratory ball mill. The physical and mechanical properties of blended cements were determined in accordance with current standards and generally accepted methods. For determining the strength class of cement according to EN 196-1 the specimens (40x40x160 mm) of the mortar based on investigated cement were prepared. After disbandment and marking, the samples were placed in water for storage until the test was performed at 2, 28 and 365 days.

To establish relationship between ecological and technical properties of concrete, clinker efficiency coefficient in concrete was determined as the ratio of cement consumption to compressive strength in a certain age $\left[\mathrm{kg} /\left(\mathrm{m}^{3} \cdot \mathrm{MPa}\right)\right]$ Compressive strength of nanomodified concretes was determined on cubic specimens (100x100x100 mm) after 1, 2 and 28 days.

\section{Research results}

Component composition of blended cements have a significant influence on the process of the compressive strength. The compressive strength of cements at age of hardening 2; 28 and 365 days is shown in Fig. 3. Early strength of blended cements is lower compared to OPC, because SCMs are characterized by lower activity than Portland cement clinker. However, after 28 days of hardening the strength of the blended cements CEM II/B-M, CEM IV/B, CEM V/A increases and corresponds to the strength class $32.5 \mathrm{R}$ and $\mathrm{MC}$ - the strength class 22.5X. Coefficients of $\mathrm{CO}_{2}$ emission of blended cements with different clinker-factor are presented at Fig. 4.

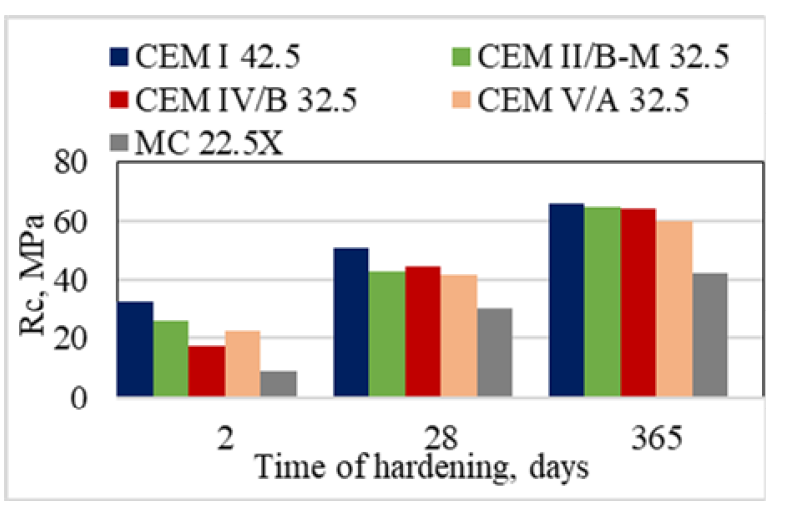

Fig. 3. Compressive strength of cements.

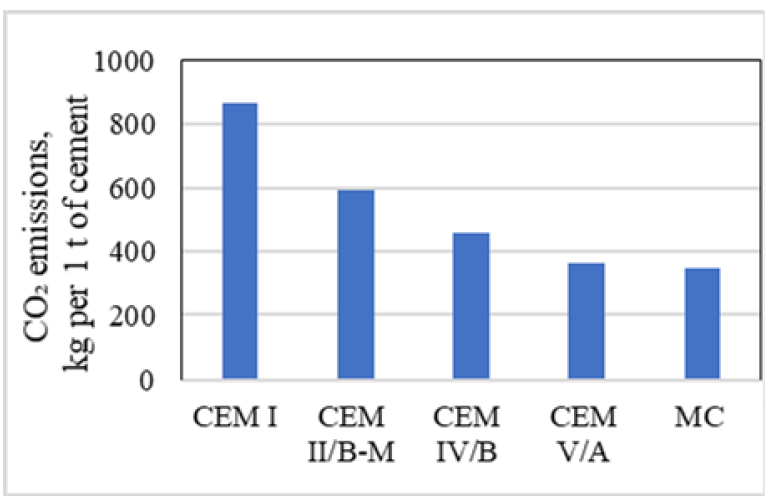

Fig. 4. $\mathrm{CO}_{2}$ emission of blended cements with different clinker-factor.

To determine effects of formulation and technological factors, concrete mixes compositions were designed using mathematical experiment planning. Experimental studies of impact of composite Portland cement CEM II/B-M and PCE superplasticizer consumption on early strength as well as clinker efficiency coefficients in concrete were performed according to a two-factor three-level experiment. Consumption of CEM II/B-M $\left(X_{I}=320 ; 370 ; 420 \mathrm{~kg} / \mathrm{m}^{3}\right)$ and amount of PCE $\left(X_{2}=0 ; 0.8 ; 1.6\right.$ wt. \%) were chosen as variable factors.

The increase of cement usage from 320 to $420 \mathrm{~kg}$ per $\mathrm{m}^{3}$ to achieve $\mathrm{OK}=16-18 \mathrm{~cm}$, a decrease in $\mathrm{W} / \mathrm{C}$ from 0.62 to 0.48 was observed. After 2 days of curing, modified concrete with cement amount of $420 \mathrm{~kg} / \mathrm{m}^{3}$ and PCE of 1.6 wt. \% had the highest strength $\left(\mathrm{f}_{\mathrm{c} 2}=47.0 \mathrm{MPa}\right)$. Calculations of concrete clinker efficiency revealed that with an increase in strength of concrete, specific consumption of clinker per unit of strength is $3.5 \ldots 3.1 \mathrm{~kg} / \mathrm{m}^{3} \mathrm{MPa}$ after 28 days. The modified clinker-efficient concretes classes C35/45... 
C40/50 are characterized by average increase of strengh $\left(\mathrm{fcm}_{2} / \mathrm{fcm}_{28}=0.32 \ldots 0.39\right)$.

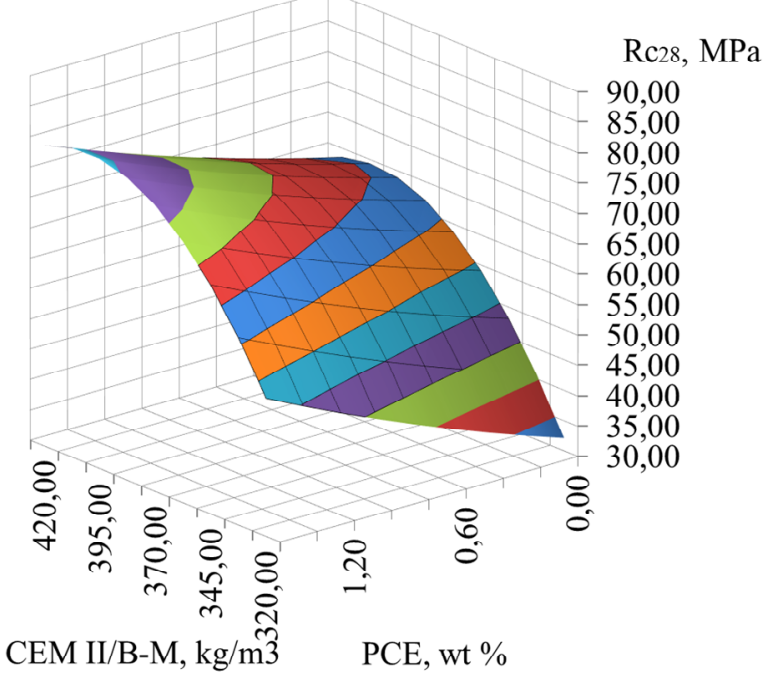

a

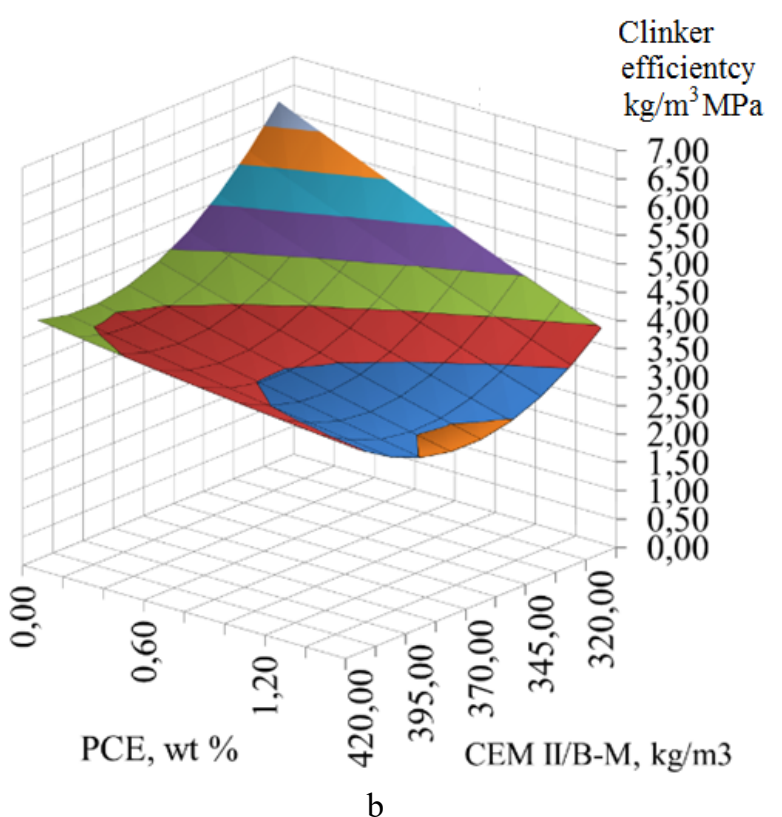

Fig. 5. Response surfaces after 28 days of hardening: concrete strength (a) and clinker efficiency (b).

Concretes with $\mathrm{W} / \mathrm{C}=0.38-0.42$ were designed to study the quality parameters of modified concrete based on low-carbon binders CEM II/B-M 32,5 R, CEM IV/B 32,5 R, CEM V/A 32,5 R, MC 22,5X. Composition of concrete by weight $\mathrm{C}$ : FA: $\mathrm{CA}=1: 1,87: 3,6$ (cement $370 \mathrm{~kg}$ per $1 \mathrm{~m}^{3}$ ). For determining workability of fresh concrete mix was measured slump of a compacted concrete cone (under the action of gravitational forces) which equal to $9.5 . .15 .0 \mathrm{~cm}$. The density of fresh concretes are $2260.2410 \mathrm{~kg} / \mathrm{m}^{3}$ and air content amount to $2.6 . .4 .5 \%$. For the investigated concrete mixes there are no bleeding due to the content of superfine zeolite in the composition of blended cements, because zeolite is characterized by porous structure and a low bleeding than GGBFS, fly ash and limestone. The strength of clinker-efficient concretes is presented in Fig. 6 and the conformity of the developed concretes based on lowcarbon cements to the Cement Industry' road map is shown in fig. 7.

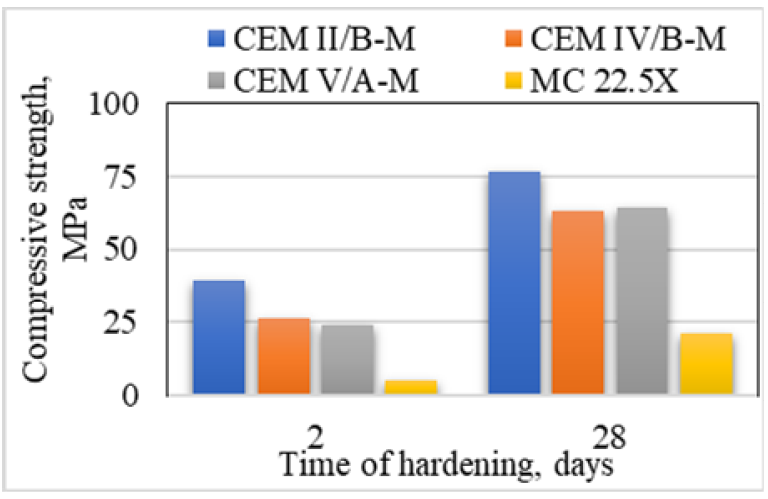

Fig. 6. Strength of clinker-efficient concretes.

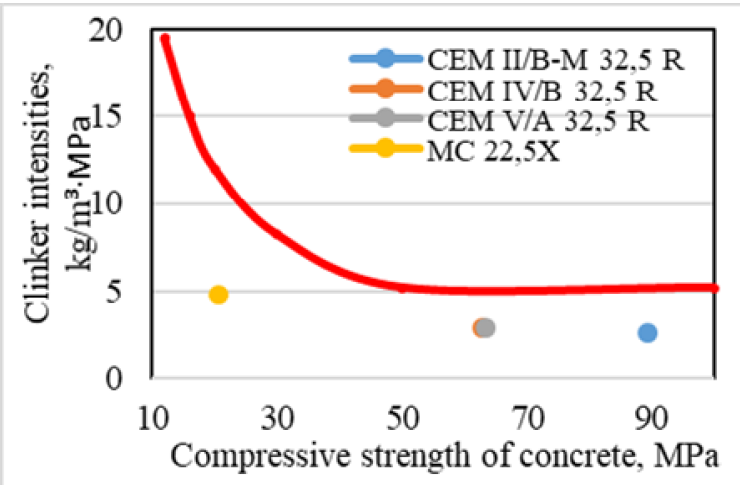

Fig. 7. Sustainable concretes based on low-carbon cements.

The possibility of using multicomponent cements in construction technology is largely determined by the properties of mortars based on them. Experimental studies have established the amount of low-carbon binder MC 22.5X for the design of mortar classes M2.5 ... M10. For mortar mixes (consistency by plunger 30-35 mm) water-cement ratio increases from 0.75 to 1.3 with reduction consumption of cement MC $22.5 \mathrm{X}$ from 465 to 198 per $1 \mathrm{~m}^{3}$ of sand. The bulk density of masonry mortars varies from 2050 to $1995 \mathrm{~kg} / \mathrm{m}^{3}$. As can be seen from Fig. 8, a, class M10 by the compressive strength for masonry mortar is achieved at the consumption of lowcarbon binder $465 \mathrm{~kg} / \mathrm{m}^{3}$. The consumption of MC $22.5 \mathrm{X}$ is $232 \ldots 348 \mathrm{~kg} / \mathrm{m}^{3}$ to provide the class M2.5...M5. Experimental studies have found that with the using $0.09 \ldots 0.18 \%$ Master Air 81 admixture with plasticizing and air-entraining action in the composition of mortars (consumption of MC 22.5X - 465..198 kg/m consistency by plunger $30-35 \mathrm{~mm}$ ) water content is reduced by $10-15 \%$ and bulk density - to $1880 \ldots 1820$ $\mathrm{kg} / \mathrm{m}^{3}$. The strength activity index after 28 days increases 1.3-1.1 times, after 90 days - 1.5-1.2 times compared to mortars without Master Air 81 (Fig. 8, b). Modified mortar with a MC $22,5 \mathrm{X}$ consumption of $465 \mathrm{~kg} / \mathrm{m}^{3}$ is characterized by the highest strength $21.0 \mathrm{MPa}$.

Consistent efforts with the goal of significant reduction of emissions of $\mathrm{CO}_{2}$ are directed to research the chemistry of cement that ensures partial or complete replacement of ordinary Portland cement by ecologically 
friendly binders [18]. Currently, the consumption of calcium sulphate plasters increases as they belong to the most ecologically friendly binders because of their low energy consumption during the production. Nevertheless, gypsum products have low water resistance. Improved structural and technical qualities of gypsum products, in particular their increased strength and water resistance are ensured by these two methods: the creation of products with low coefficient of water/gypsum or the introduction of Portland cement and active mineral additives to the gypsum binder [19, 209].
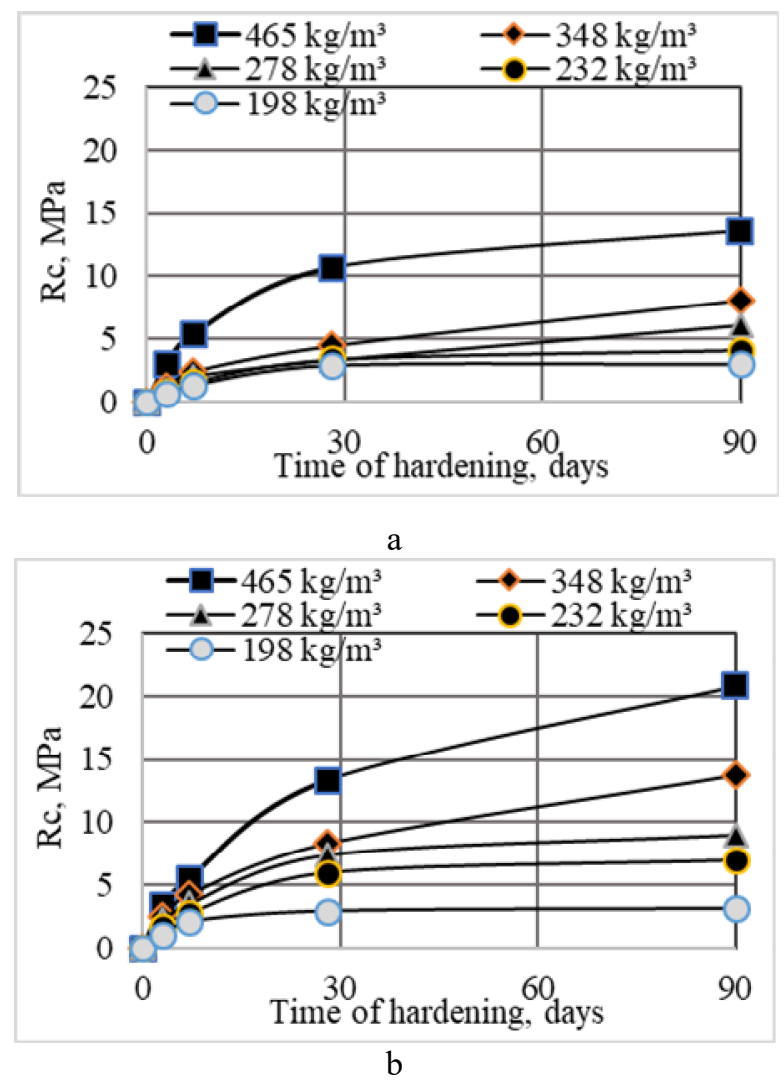

Fig. 8. Compressive strength of mortars based on MC 22,5X: without admixture (a); with Master Air 81 (b).

In gypsum binder, the carbon footprint factor $(140.7 \mathrm{~kg} \mathrm{CO} / \mathrm{t})$ is lower by $4.0-6.0$ compared to Portland cements. However, the gypsum binder is characterized by a very low (5.0-7.0 MPa) compressive strength and low water resistance. Combining different types of binding substances allows production of strong and water resistance low-carbon dioxide emission composites. The strength of a composite binder based on 75 wt. $\%$ G- $6+25$ wt. $\%$ MC22.5X in 28 days reaches 20 $\mathrm{MPa}$ and in 2.3 times exceeds the strength of building plaster. Due to hardening because of pozzolanic reaction, the strength increases even more and the water resistance corresponds to the hydraulically hardened binders. Simultaneously, the carbon footprint $(163.0 \mathrm{~kg} \mathrm{CO} / \mathrm{t})$ of this composite binder is only by $15.8 \%$ higher than one of building plaster, but is significantly lower in comparison to ordinary Portland binder.

The zeolite-based composite plaster binders modified by polycarboxylate's superplasticizers are even more strength and softening coefficient (Fig. 9). They are water resistant, durable and can be utilized for the production of building mortars, dry mixtures for plaster, restoration works, as well as partitions and walls in wet rooms, for the formation of bulky elements of sanitary cabinets, for devices of self-leveling screeds under a floor.
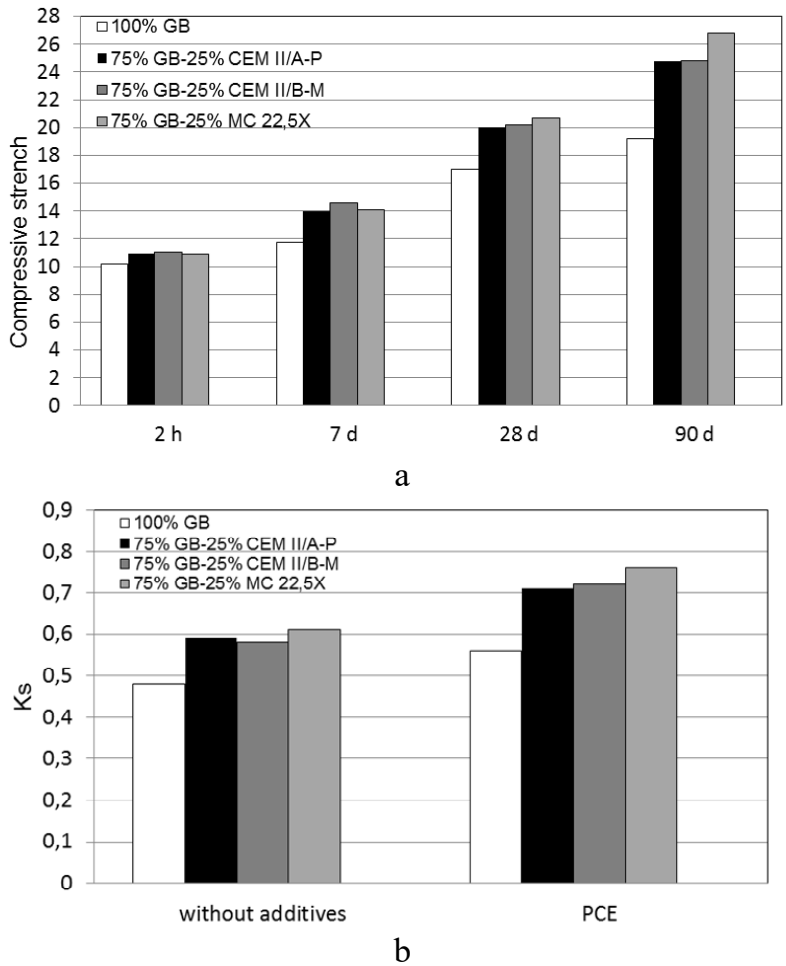

Fig. 9. Compressive strength (a) and softening coefficient (b) of composite gypsum binders with PCE admixture.

Particularly noteworthy is the use of composite gypsum binder for the manufacture of lightweight concrete - arbolite based on composite binders, organic fillers (up to $50-60 \%$ of the volume) and chemical additives [21]. Blocks using composite binder based on gypsum, cement and superzeolite, as well as hemp as a filler are sustainable, heat resistant, humidity-free - and carbon negative. A hemp houses could be greener, fireresistant and built quicker than using lightweight expanded clay concrete.

Modified multi-component composite binders containing superfine zeolite and carbonate microfillers can significantly reduce the power consumption during production of various construction materials and decrease carbon footprint, that correspond to the goals of sustainable development in the construction.

\section{Conclusions}

Development of low-carbon multicomponent cements and modified clinker-efficient concretes and mortars based on them allows to create progressive models of rational use of natural raw materials, fuel, electricity, utilize production wastes, reduce greenhouse gas emissions and solve a number of important environmental, economic and social problems. The urgency of developing the basics of low-carbon cements technologies is in line with the global concept of 
sustainable development and life cycle approach with rational use and saving of material and energy resources and is determined by the possibility of reducing $\mathrm{CO}_{2}$ emissions by 2.5-4.0 times while reducing the content of clinker component.

The compositions of gypsum, Portland cement clinker, pozzolan zeolite-containing components, as well as the use of polycarboxylate superplasticizers allows to produce environmentally friendly modified composite gypsum binders with the increased water resistance. The multicomponent gypsum binders with the preservation of the positive properties of gypsum products and the acquisition of hydraulic properties of Portland cement promotes the development of hydraulic properties, the increase in strength, water resistance and durability of composite gypsum products as a whole. The hempcrete articles based on composite binders are sustainable, heat resistant, humidity-free - and carbon negative.

\section{References}

1. M. Schneider, The cement industry on the way to low-carbon future. Cem. Concr. Res. 124, 1-19 (2019). doi:10.1016/j.cemconres.2019.105792

2. S.A. Miller, V.M. John, S.A. Pacca, A. Horvath, Carbon dioxide reduction potential in the global cement industry by 2050 . Cem. Concr. Res. 114, 115-124 (2018). doi:10.1016/j.cemconres.2017.08.026

3. The role of cement in the 2050 low carbon economy (CEMBUREAU, 2013), https://cembureau.eu/newsviews/publications. Accessed 25 Sep 2013

4. T. Proske, M. Rezvani, S. Palm, Ch. Müller, C.-A. Graubner. Concretes made of efficient multicomposite cements with slag and limestone. Cem. Concr. Comp. 89, 107-119 (2018). doi.org/10.1016/j.cemconcomp.2018.02.012

5. K.L. Scrivener, V.M. John, E.M. Gartner, et al., Eco-efficient cements: Potential economically viable solutions for a low- $\mathrm{CO}_{2}$ cement-based materials industry. Cem. Concr. Res. 114, 2-26 (2018). doi:10.1016/j.cemconres.2018.03.015

6. B. Gerd, M. Zajac, J. Skocek, B.M. Haha, Development of composite cements characterized by low environmental footprint. J. Clean. Prod. 226, 503-514 (2019). doi:10.1016/j.jclepro.2019.04.050

7. K. Yang, Y. Jung, M. Cho, S. Tae, Effect of supplementary cementitious materials on reduction of $\mathrm{CO}_{2}$ emissions from concrete. J. Clean. Prod. 103, 774-783 (2015). doi:10.1016/j.jclepro.2014.03.018

8. Z. Giergiczny, Fly ash and slag. Cem. Concr. Res. 124, 1-18 (2019). doi:10.1016/j.cemconres.2019.105826

9. J. Kuterasińska, A. Krol, Econom. Environ. Stud. A 16, 3 (2016)

10. E. Smrckova, M. Bacuvcik, and I. Janotka, Basic Characteristics of Green Cements of CEM V/A and
CEM V/B Kind. Adv. Mater. Res. 897, 196-199 (2014). doi:10.4028/www.scientific.net/amr.897.196

11. J.J. Chen, L.G. Li, P.L. Ng, A.K.H. Kwan, Effects of superfine zeolite on strength, flowability and cohesiveness of cementitious paste. Cem. Concr. Compos. 83, 101-110 (2017). doi:10.1016/j.cemconcomp.2017.06.010

12. R. Firdous, D. Stephan, J.N.Y. Djobo. Natural pozzolan based geopolymers: A review on mechanical, microstructural and durability characteristics. Constr. Build. Mater. 190, 12511263 (2018). doi:10.1016/j.conbuildmat.2018.09.191

13. T. Kropyvnytska, M. Sanytsky, T. Rucinska, O. Rykhlitska, Development of nanomodified rapid hardening clinker-efficient concretes based on composite Portland cements. EEJET 6, 38-48 (2019). doi:10.15587/1729-4061.2019.185111

14. M. Limbachiya, S.C. Bostanci, H. Kew, Suitability of BS EN 197-1 CEM II and CEM V cement for production of low carbon concrete. Constr. Build. Mater. 71, 397-405 (2014). doi:10.1016/j.conbuildmat.2014.08.061

15. P. Sikora, E. Horszczaruk, T. Rucinska, The Effect of Nanosilica and Titanium Dioxide on the Mechanical and Self-Cleaning Properties of WasteGlass Cement Mortar. Procedia Eng. 108, 146-153 (2015). doi:10.1016/j.proeng.2015.06.130

16. P. Krivenko, R. Runova, I. Rudenko, V. Skorik, V. Omelchuk, Analysis of plasticizer effectiveness during alkaline cement structure formation. EEJET 4, 35-41 (2017). doi:10.15587/17294061.2017.106803

17. P. Krivenko, V. Gots, O. Petropavlovsskyi, I. Rudenko, O. Konstantinovskyj, A. Kovalchuk. Development of solutions concerning regulation of proper deformations in alkali-activated cements. EEJET 5, 24-32 (2019). doi:10.15587/17294061.2019.181150

18. N. Lushnikova, L. Dvorkin, in Sustainability of Construction Materials, 2nd edn., ed. by J.M. Khatib (Elsevier, Woodhead Publish., 2016)

19. A. Vimmrova, M. Keppert, O. Michalko, R. Cerny, Calcined gypsum-lime-metakaolin binders: Design of optimal composition. Cem. Concr. Comp. 52, 9196 (2014). doi:10.1016/j.cemconcomp.2014.05.011

20. M. Sanytsky, T. Kropyvnytska, H.-B. Fischer, N. Kondratieva, Performance of low carbon modified composite gypsum binders with increased water resistance. Chem. Chem. Technol. 13, 495-502 (2019). doi:10.23939/chcht13.04.495

21. D. Barnat-Hunek, P. Smarzewski, S. Fic, Compos. Theor. Pract. A 15, 21 (2015) 